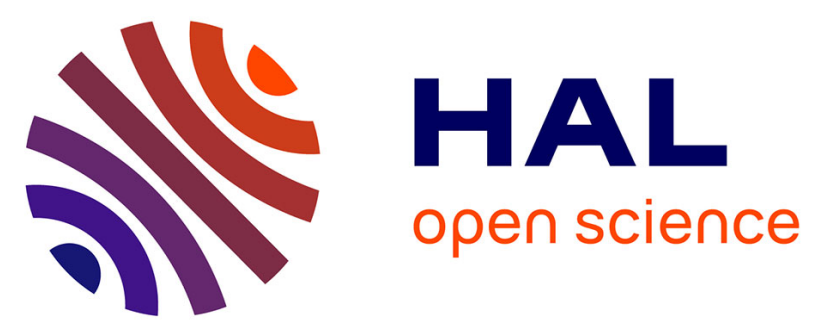

\title{
Measurement by vertical scanning profilometry of resorption volume and lacunae depth caused by osteoclasts on dentine slices
}

Florence Pascaretti-Grizon, Guillaume Mabilleau, Michel-Félix Baslé, Daniel

Chappard

\section{To cite this version:}

Florence Pascaretti-Grizon, Guillaume Mabilleau, Michel-Félix Baslé, Daniel Chappard. Measurement by vertical scanning profilometry of resorption volume and lacunae depth caused by osteoclasts on dentine slices. Journal of Microscopy, 2011, 241 (2), pp.147-152. 10.1111/j.1365-2818.2010.03410.x . hal-03262089

\section{HAL Id: hal-03262089 \\ https://univ-angers.hal.science/hal-03262089}

Submitted on 16 Jun 2021

HAL is a multi-disciplinary open access archive for the deposit and dissemination of scientific research documents, whether they are published or not. The documents may come from teaching and research institutions in France or abroad, or from public or private research centers.
L'archive ouverte pluridisciplinaire HAL, est destinée au dépôt et à la diffusion de documents scientifiques de niveau recherche, publiés ou non, émanant des établissements d'enseignement et de recherche français ou étrangers, des laboratoires publics ou privés. 


\title{
Measurement by vertical scanning profilometry of resorption volume and lacunae depth caused by osteoclasts on dentine slices
}

\author{
F. PASCARETTI-GRIZON*, G. MABILLEAU $\dagger$, M.F. BASLE* \\ \& D. CHAPPARD* \\ *INSERM, U 922-LHEA “Remodelage Osseux et Biomatériaux”, Faculté de Médecine, Cédex, \\ France \\ $\dagger$ Nuffield Department of Orthopaedics, Rheumatology and Musculoskeletal Science, The Botnar \\ Research Centre, Nuffield Orthopaedic Centre Headington, Oxford University Institute \\ of Musculoskeletal Sciences, Oxford, U.K.
}

Key words. Dentine slice, eroded surfaces, eroded volume, osteoclast, osteolysis, vertical scanning profilometry.

\begin{abstract}
Summary
The resorption pit assay is classically used to evaluate osteoclast activity on bone or dentine slices that can be eroded by these cells. Two different types of cells were generated from peripheral blood mononuclear cells cultured in the presence of M-CSF + sRANKL or with M-CSF + LPS. At the end of the culture period ( 21 days), cells were discarded and the dentine slices stained with toluidine blue and examined with an NT9100 Wyco vertical scanning profilometer. The images of the dentine surface were corrected for tilt and the eroded volume was calculated on the whole images. The depth of the eroded pits was determined. The data files were used to reconstruct the surface of the slices by standardizing the ground level to compare both conditions. Osteoclasts generated with M-CSF + sRANKL were capable of resorbing a more important volume than those generated with MCSF + LPS. In addition, the formers were able to resorb the dentine matrix more deeply. Data provided by the microscope were used to reconstruct three-dimensional images of the dentine slices with pseudo colours varying with the depth of erosion. Vertical scanning profilometry, a technique used to measure the roughness of polished or etched surfaces in metallurgic industry, can be used to accurately measure the eroded volume and the mean erosion depth done by osteoclasts in the resorption pit assay.
\end{abstract}

\section{Introduction}

Bone is a living and dynamic tissue, which constantly adapts to strains and endocrine changes by remodelling.

Correspondence to: Daniel Chappard, INSERM, U 922-LHEA "Remodelage Osseux et Biomatériaux”, Faculté de Médecine, 49045 Angers Cédex, France. e-mail: daniel.chappard@univ-angers.fr
Bone remodelling is a temporo-spatially coupled mechanism in which 'old' bone is resorbed by osteoclasts followed by apposition of 'new' bone packets by osteoblasts. Osteoclasts are giant multinucleated cells, which usually contain 1020 nuclei (Roodman, 2006). They are formed by fusion of haematologic precursors created by the differentiation of the CFU-GM (colony forming unit-granulocyte-macrophage) in the bone marrow microenvironment under a number of particular cytokines (Roodman, 2006). These precursors express the RANK receptor at their surface (receptor activator of NF- $\kappa$ B) (Boyle et al., 2003). Contacts with stromal cells (or with osteoblasts), which express RANK ligand induce cell fusion to form a polykaryon. Macrophage colony stimulating factor (M-CSF) is necessary to achieve their differentiation (Burger et al., 1982). Osteoclasts differ from macrophage polykaryons by possessing specialized machinery for resorbing the calcified bone matrix. Osteoclasts are capable to attach firmly onto the bone surface via $\alpha_{\mathrm{v}} \beta_{3}$ integrins coupled to an actin ring at the cell periphery, in the sealing zone. A ruffled border (a specialized area of the membrane under the cell and limited by sealing zone) limits a resorption chamber where $\mathrm{H}^{+} \mathrm{Cl}^{-}$and collagenolytic enzymes such as cathepsin $\mathrm{K}$ are released. Bone matrix is first decalcified by protons and, when the mineral has been solubilized, the cathepsin $\mathrm{K}$ can break the collagen fibres into large fragments that are endocytosed (Gowen et al., 1999). Collagen breakdown is terminated in transcytotic vesicles with the hydrolytic tartrate resistant acid phosphatase (TRAcP) (Vääraniemi et al., 2004). Although the RANK-RANKL system is the key mechanism to produce osteoclasts in vivo (with the adjunction of MCSF), a number of studies have found that other cytokines or factors can lead to the formation of osteoclasts or to activate the preexisting osteoclasts (Mabilleau \& Sabokbar, 2009). Among them, lipopolysaccharides (LPS) have been 
proposed as an additional mechanism by acting via the tolllike receptor 4 (Kikuchi et al., 2001) and injections of LPS in rat periodontal tissues are followed by the appearance of active osteoclasts (Umezu et al., 1989). In a number of studies, the activity of osteoclasts has been evaluated by placing isolated osteoclasts onto slices of cortical bone or dentine (Boyde et al., 1984). The method was used to evaluate the activity of various drugs such as bisphosphonates (Takami et al., 2003), corticosteroids (Hirayama et al., 2002) and strontium (Takahashi et al., 2003). In addition, it was also used to characterize the resorbing capacities of osteoclasts isolated from transgenic animals (Boyce et al., 1992; Umezu et al., 1989). However, in most studies the resorption pits are quantified after staining with toluidine blue and the only parameter consists in measuring the mean area of eroded surface by image analysis. Osteoclast activity should be quantified in term of volume resorbed or in term of depth of the eroded pits but these parameters can hardly be measured. The development of new microscopic technologies such as vertical scanning profilometry may help to solve the problem. This study aims at measuring the eroded amount of bone on dentine slices produced by two types of osteoclasts generated either by M-CSF and sRANKL or LPS from peripheral mononucleated blood cells.

\section{Material and methods}

\section{Preparation of dentine slices}

Dentine slices were made as previously described (Fujikawa et al., 1996). Briefly, an elephant task was sectioned into slices (100-150 $\mu \mathrm{m}$ thickness). Dentine disks were made by cutting the dentine slices with a 6-mm-diameter punch. Dentine disks were then sonicated in water, sterilised by immersion into ethanol for $1 \mathrm{~h}$ and dried overnight.

\section{Osteoclast preparation}

Peripheral blood mononuclear cells were isolated as previously described (Mabilleau \& Sabokbar, 2009). Blood was diluted 1:1 in $\alpha$-minimal essential medium (Invitrogen, Paisley, U.K.), layered onto Histopaque (Sigma-Aldrich Chemicals, Poole, U.K.), and centrifuged (693 g) for $20 \mathrm{~min}$. The interface layer was re-suspended in minimal essential medium then centrifuged $(600 \mathbf{g})$ for a further $10 \mathrm{~min}$ after which the resultant cells were re-suspended in media supplemented with $10 \%$ heat inactivated fetal calf serum (Invitrogen, Paisley, U.K.) and counted in a haemocytometer following lysis of red blood cells by a $5 \%(\mathrm{v} / \mathrm{v})$ acetic acid solution.

Isolated human peripheral blood mononuclear cells $\left(5 \times 10^{5}\right.$ cells $)$ were cultured at the surface of dentine slices in minimal essential medium containing $100 \mathrm{UI} / \mathrm{mL}$ penicillin, $100 \mu \mathrm{g} / \mathrm{mL}$ streptomycin and 10\% fetal calf serum. After $2 \mathrm{~h}$ incubation, cultures were vigorously rinsed in medium to remove nonadherent cells, and then maintained in $1 \mathrm{~mL}$ minimal essential medium/fetal calf serum with $25 \mathrm{ng} / \mathrm{mL}$ recombinant human M-CSF (R\&D Systems, Abingdon, U.K.) $\pm 100 \mathrm{ng} / \mathrm{mL}$ recombinant human soluble RANKL (Peprotech Ltd., London, U.K.) or $100 \mathrm{ng} / \mathrm{mL}$ LPS (Strain 055:B5, Sigma Aldrich Chemicals) for up to 21 days. All factors were replenished every 2-3 days.

At the end of the culture period, the dentine slices were removed from the culture wells, placed in $\mathrm{NH}_{4} \mathrm{OH}(1 \mathrm{~N})$ for $30 \mathrm{~min}$ and sonicated for $5 \mathrm{~min}$ to remove any adherent cells. The slices were then washed in distilled water, stained with $0.5 \%(\mathrm{w} / \mathrm{v})$ aqueous toluidine blue, to allow examination of the eroded surfaces by conventional light microscopy. After air drying, slices were mounted onto a glass slide with a synthetic medium (NeoEntellan ${ }^{\circledR}$, Merck, Fontenay-sous-bois, France) to preserve surface flatness as much as possible.

\section{The vertical scanning profilometer}

Optical interferometric measurements were done using a Wyko NT9100 optical profiling system (Veeco, Instruments SAS, Dourdan, France), a system originally dedicated to the measurement of roughness in material samples. The microscope is based on light interferometry and operates as a noncontact optical profiler in vertical scanning interferometry mode (VSI) to produce three-dimensional (3D) topography maps of the sample surface. Briefly, a white light source is emitted by conventional light source and is split into two beams which pass through a Mirau's interferometric objective. This objective consists of a lens, a reference mirror and a beamsplitter. The incident beams are reflected from the reference mirror and the sample surface, respectively. The light reflected from this mirror combines with the light reflected from the sample to produce interference fringes (known as interferogram); where the best-contrast fringe occurs at best focus. The light and dark fringes are used in combination with the wavelength of the light to determine height difference between each fringe. A piezo-electric stage moves the sample vertically with a nanometre precision, which produces phase shifts in the interferogram. Interferograms are digitized using a charge-coupled device camera and the data are analysed to produce a topographic surface map. The software Vision ${ }^{\mathrm{TM}}$ (release 4.10, Wyco) was used to acquire and analyse the data. In this study, the entire surface of the dentine slices was measured at a magnification of $200 \times$ using an $x y$ motorized stage. For each dentine slice, six images were randomly chosen and analysed. As the slides were not perfectly flat during acquisition, the tilt introduced was compensated by a facility of the Vision software. It minimizes the angle of the sample relative to the reference optics so that slanted samples appear flat. Then, the surface of the unresorbed dentine slice was set as the zero level. The eroded volume on the whole image and the depth of eroded surfaces were measured using volume parameters and surface profile facilities (Fig. 1). For measuring 


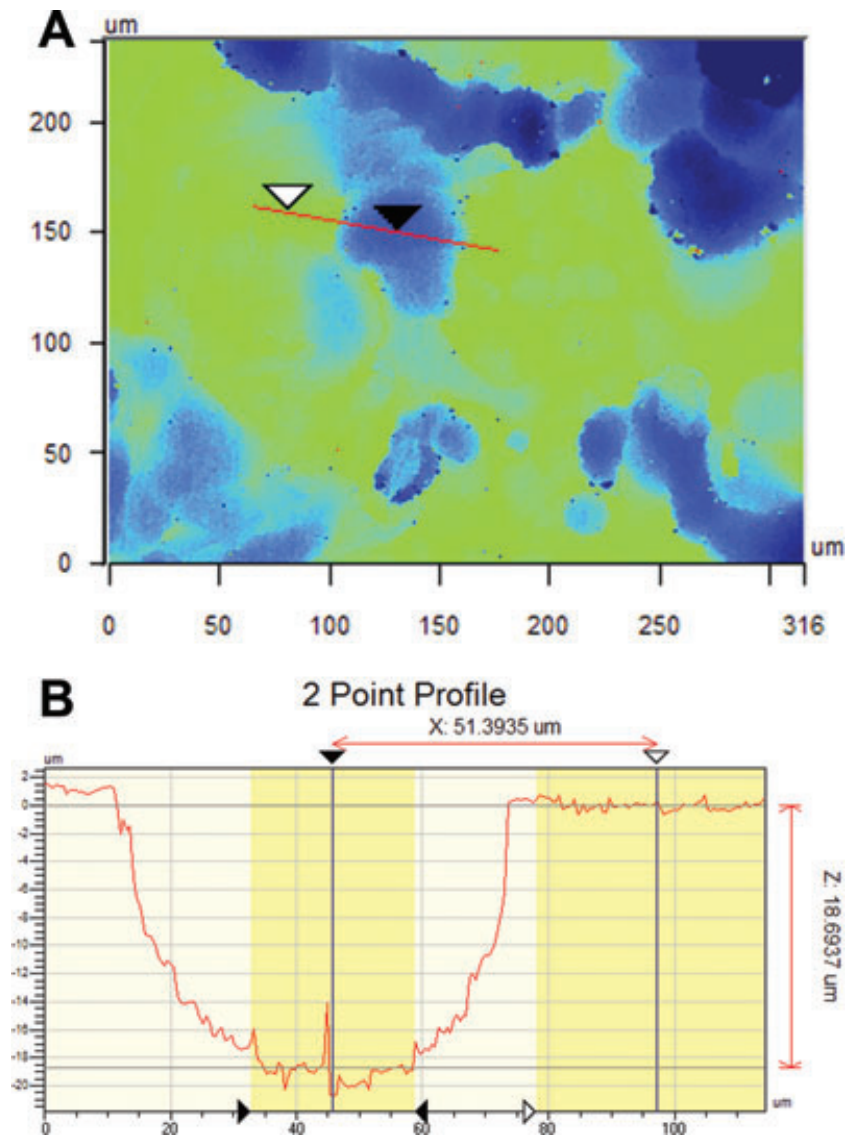

Fig. 1. Measurement of the depth of a resorption pit created by an osteoclast generated with M-CSF + sRANKL on the dentine surface. (A) Two-dimensional image of the dentine surface, the straight line is drawn to obtain the profile of the erosion pit; (B) section of the profile of the erosion pit and automatic measurement of the erosion depth.

erosion depth, a vector was drawn over on the whole width of the eroded pit and covered the margins on the ground surface. Data were expressed in $\mu \mathrm{m}^{3}$ of eroded volume and $\mu \mathrm{m}$ of erosion depth. During measurement, some pixels were discarded because they were not reflective and data may not be recorded. The data restore facility was used to remove these missing data by local interpolation. Files of processed data were saved in the.asc format for Matlab imaging.

\section{Matlab $^{\mathrm{TM}}$ imaging}

Because the 3D images produced by the Vision ${ }^{\mathrm{TM}}$ software cannot be standardized for comparison between slides, the.asc files were uploaded in Matlab ${ }^{\mathrm{TM}} 7.0$ (The MathWorks Inc., Natick, MA, U.S.A.). The remaining aberrant pixels were discarded by a $3 \times 3$ median filter and the values were standardized to set the specimens at the same ground level. Then, the 3D images of the surfaces were reconstructed with the image toolbox environment using the Phong's reflection model in which light rendering is obtained by an interpolation method (per-pixel lighting) (Phong, 1975). The method is considered superior to the Gouraud's algorithm, which can produce some errors and pixellization in highly contrasted images.

\section{Statistical analysis}

Statistical analysis was performed with the Systat ${ }^{\circledR}$ statistical software release 11.0 (Systat Inc., San José; CA, U.S.A.). The intrarater coefficient of variation was determined as the standard deviation divided by the sample mean of 5 measured performed by the same examiner. Differences between groups were analysed by Mann-Whitney's $U$ test. Differences were considered as significant when $P<0.05$.

\section{Results}

At the end of the incubation period, the dentine slices exhibited a completely different pattern of eroded surfaces between the two slice series. Slices incubated with M-CSF + sRANKL had large and scalloped resorption ruts while cells incubated with M-CSF + LPS exhibited only minute pits. The volume of eroded bone per slice considerably varied between the two treatments (Fig. 2A). The intrarater coefficient of variation determined on five consecutive measurement series was 3.4\% for the eroded volume. Similarly, the depth of the eroded areas was considerably reduced with M-CSF + LPS treated cells (Fig. 2B). The Vision ${ }^{\mathrm{TM}}$ software allowed a 3D imaging of the surface but standardization was not possible thus impairing the comparison between images. When data were transferred to Matlab ${ }^{\mathrm{TM}}$, it was possible to normalize the surface between the images, thus the unresorbed flat areas were set to the same level. Resorbed areas were more easily identified and the depth was evidenced by pseudo colours (Fig. 3)

\section{Discussion}

In vitro models of bone resorption using disaggregated osteoclasts have been proposed on bone or dentine slices (Boyde et al., 1984; Chambers et al., 1984). Dentine slices are often preferred since they do not contain holes (e.g. Haversian canals in compact bone) that create surface irregularities and imperfections. Synthetic calcium/phosphate substrates have also been proposed but they do not reflect the physiological activities of the osteoclasts, which decalcify and hydrolyze collagen fibres at the same time (Paul-Clark et al., 2002; Yamada et al., 2007). Measurement of resorption activity is most often done by considering the surface of the resorption pits after staining with toluidine blue and image analysis. However, a number of methods have been proposed to analyse the volume and the depth of the erosion pits. Scanning electron microscopy has been proposed since the pioneering works of Boyde et al. (1984) and can be combined with image analysis of the images (Grimandi et al., 2006). The used of 


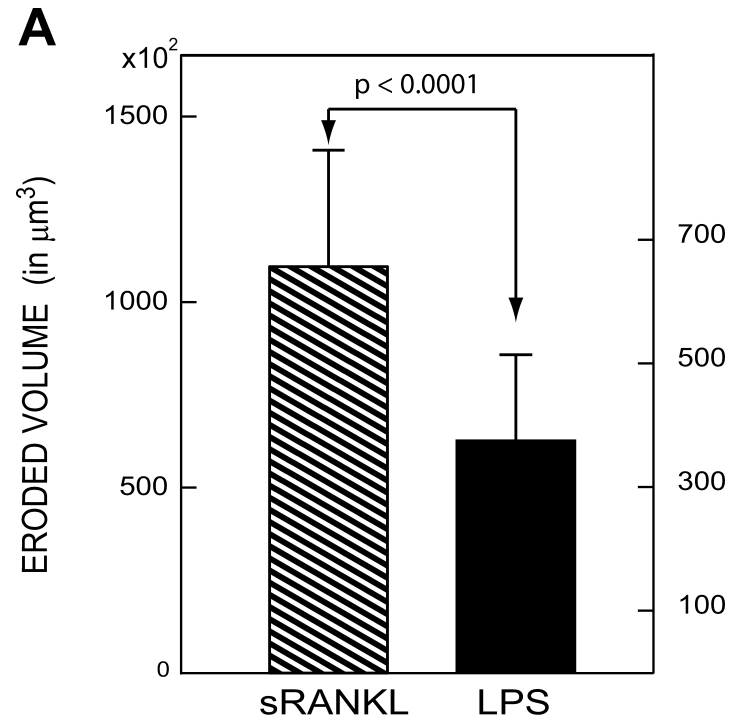

B

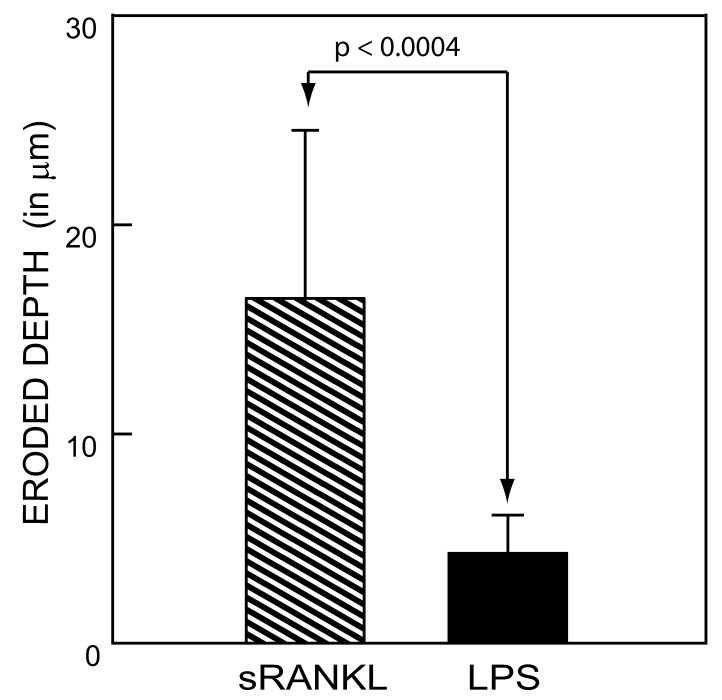

Fig. 2. (A) comparison of the eroded volume of dentine resorbed by osteoclasts generated with M-CSF + sRANKL (dashed lines) or M-CSF + LPS. (B) Comparison of the mean erosion depth. The bars represent the standard deviations.

stereoscopic images obtained after tilting the electron beam of the scanning electron microscopy was the first method that allowed a topographic map and a 3D reconstruction of the eroded areas (Fuller et al., 1994). However, this method is time-consuming and does not allow measurements on the whole slice. A technique using wide-field microscopy, reflected light and comparison with control impacts obtained with a diamond microdurometer was proposed (Walsh et al., 1991). Confocal laser microscopy has been found suitable to evaluate the resorption depth and volume created on synthetic calcium/phosphate materials but the image proposed are not realistic enough (Yamada et al., 2007). The method has also
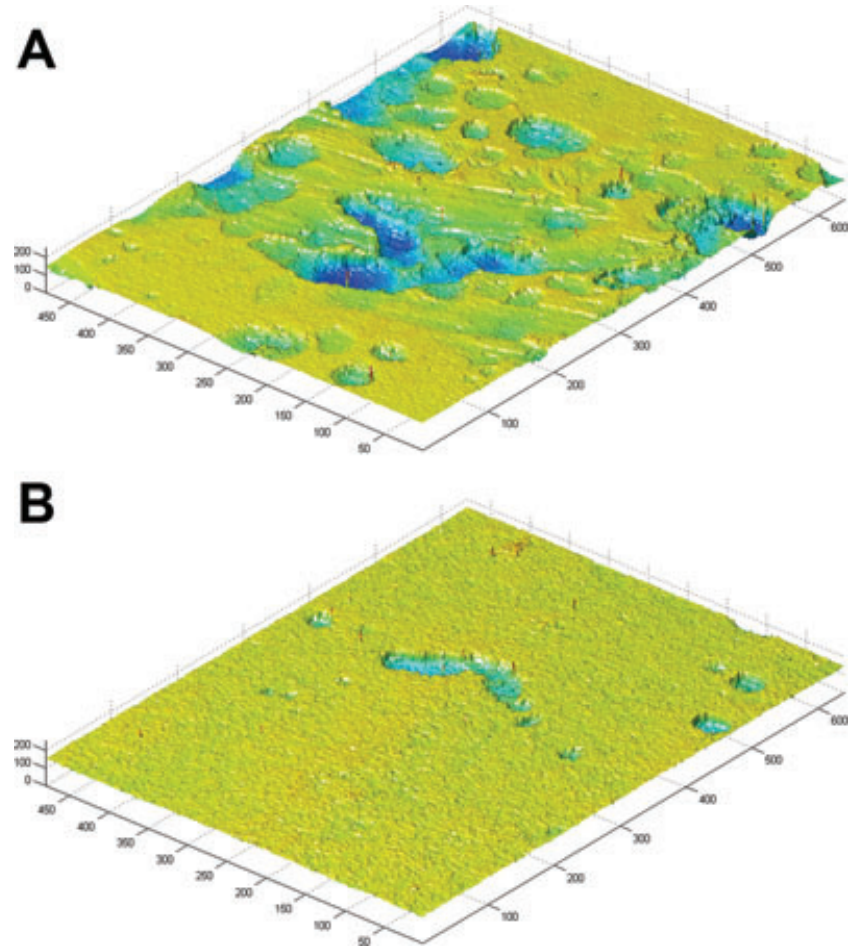

Fig. 3. Three-dimnensional imaging of the eroded surfaces obtained with M-CSF + sRANKL or M-CSF + LPS generated osteoclasts. The ground surfaces have been set at the same level for comparison.

been used to evaluate the resorption depth of osteoclast treated by the NBD-peptide, an inhibitor of the NF-kappaB pathway (Soysa et al., 2009). Contact profilometry can measure the depth of individual resorption pits and provides an estimation of the mean roughness of the material surface [e.g. Ra, Rq parameters or $\mathrm{Pz}$ (average resorption depth)] (Schwartz et al., 2000; Fusi et al., 2005; Ren et al., 2009). However, these parameters are useful to characterize the roughness of polished or etched material surfaces but have little interest to estimate the volume of eroded material. Indirect estimation of the volume can be obtained by measuring the amount of collagen released (Breuil et al., 1998) or the release of $\mathrm{Ca}^{2+}$ from dentine slices (Sugawara et al., 1998). The present technique is a more simple approach using vertical scanning profilometry, a technique initially proposed to measured metallographic surfaces; in addition, it provides realistic images close to those obtained by scanning electron microscopy. The method allows a direct and unbiased measurement of the eroded depth and volume. In the present study, we found that osteoclasts, generated by two different cytokine pathways, had different resorptive capacities. This is of interest since mononucleated osteoclast precursors have been found to resorb less bone on a resorption pit assay on bone slices (Prallet et al., 1992). Similarly, human studies have confirmed that osteoclasts generated by different cytokine networks in various types of lymphocyte B malignancies have marked 
differences in erosion capacity in multiple myeloma, (they can resorb deeply the bone matrix) while osteoclasts from Waldenström disease or chronic lymphocyte leukaemia are responsible for microresorption (Marcelli et al., 1988; Josselin et al., 2009). It has also been shown that the intermediate skeleton of teleosts (which is made of chondroid bone) can be remodelled by both mononucleated and large multinucleated osteoclasts in adult fishes (Witten \& Huysseune, 2009; Witten et al., 2001). However, mononucleated osteoclasts expressing TRAcP predominate in the early skeletal development in all teleosts. In this study, the osteoclasts generated by M-CSF + sRANKL were capable to resorb a larger amount of bone and deeper than those obtained with M-CSF + LPS. The former cells were somewhat larger $(60-80 \mu \mathrm{m}$ in diameter vs. 30-40 $\mu \mathrm{m}-$ data not shown). The mean resorption depth obtained by the vertical scanning profilometer with M-CSF + sRANKL generated osteoclasts is similar to values obtained by others on the same model with disaggregated osteoclasts (approximately $20 \mu \mathrm{m}$ in depth) (Fusi et al., 2005). Vertical scanning profilometry appears as a new tool in bone biology to measure and image the eroded surfaces dug by osteoclasts on dentine or bone slices. It is the first method that allows the direct measurement of the whole eroded volume on a dentine slice.

\section{Acknowledgements}

The authors thank Mrs. Laurence Lechat for secretarial assistance. This work was made possible by grants from Contrat Region Pays de la Loire: Bioregos2 program.

\section{References}

Boyce, B.F., Yoneda, T., Lowe, C., Soriano, P. \& Mundy, G.R. (1992) Requirement of pp60(c-src) expression for osteoclasts to form ruffled borders and resorb bone in mice. J. Clin. Invest. 90, 1622-1627.

Boyde, A., Ali, N.N. \& Jones, S.J. (1984) Resorption of dentine by isolated osteoclasts in vitro. Br. Dent. J. 156, 216-220.

Boyle, W.J., Simonet, W.S. \& Lacey, D.L. (2003) Osteoclast differentiation and activation. Nature 423, 337-342.

Breuil, V., Cosman, F., Stein, L., Horbert, W., Nieves, J., Shen, V., Lindsay, R. \& Dempster, D.W. (1998) Human osteoclast formation and activity in vitro: effects of alendronate. J. Bone Miner. Res. 13, 1721-1729.

Burger, E.H., Van Der Meer, J.W., van de Gevel, J.S., Gribnau, J.C., Thesingh, G.W.\& van Furth, R. (1982) In vitro formation of osteoclasts from long-term cultures of bone marrow mononuclear phagocytes. J. Exp. Med. 156, 1604-1614.

Chambers, T.J., Revell, P.A., Fuller, K. \& Athanasou, N.A. (1984) Resorption of bone by isolated rabbit osteoclasts. J. Cell Sci. 66, 383399.

Fujikawa, Y., Quinn, J.M.W., Sabokbar, A., McGee, J.O. \& Athanasou, N.A. (1996) The human osteoclast precursor circulates in the monocyte fraction. Endocrinology 137, 4058-4060.

Fuller, K., Thong, J.T., Breton, B.C. \& Chambers, T.J. (1994) Automated three-dimensional characterization of osteoclastic resorption lacunae by stereoscopic scanning electron microscopy. J. Bone Miner. Res. 9, $17-23$.

Fusi, F., Mercatelli, L., Basile, V., Pucci, M., Siano, S., Antonio Bernabei, P. \& Monici, M. (2005) A new method based on contact surface profilometry for quantitative measurement of resorbed bone volume. Phys. Med. 21, 41-46.

Gowen, M., Lazner, F., Dodds, R., et al. (1999) Cathepsin K knockout mice develop osteopetrosis due to a deficit in matrix degradation but not demineralization. J. Bone Miner. Res. 14, 1654-1663.

Grimandi, G., Soueidan, A., Anjrini, A.A., et al. (2006) Quantitative and reliable in vitro method combining scanning electron microscopy and image analysis for the screening of osteotropic modulators. Microsc. Res. Tech. 69, 606-612.

Hirayama, T., Sabokbar, A. \& Athanasou, N.A. (2002) Effect of corticosteroids on human osteoclast formation and activity. J. Endocrinol. 175, 155-163.

Josselin, N., Libouban, H., Dib, M., Ifrah, N., Legrand, E., Basle, M.F., Audran, M. \& Chappard, D. (2009) Quantification of dendritic cells and osteoclasts in the bone marrow of patients with monoclonal gammopathy. Pathol. Oncol. Res. 15, 65-72.

Kikuchi, T., Matsuguchi, T., Tsuboi, N., et al. (2001) Gene expression of osteoclast differentiation factor is induced by lipopolysaccharide in mouse osteoblasts via Toll-like receptors. J. Immunol. 166, 35743579 .

Mabilleau, G. \& Sabokbar, A. (2009) Interleukin-32 promotes osteoclast differentiation but not osteoclast activation. PLoS One 4, e4173.

Marcelli, C., Chappard, D., Rossi, J.F., Jaubert, J., Alexandre, C., Dessauw, P., Baldet, P. \& Bataille, R. (1988) Histologic evidence of an abnormal bone remodeling in B-cell malignancies other than multiple myeloma. Cancer 62, 1163-1170.

Paul-Clark, M.J., Mancini, L., Del Soldato, P., Flower, R.J. \& Perretti, M. (2002) Potent antiarthritic properties of a glucocorticoid derivative, NCX-1015, in an experimental model of arthritis. Proc. Natl. Acad. Sci. U.S.A. 99, 1677-1682.

Phong, B.T. (1975) Illumination for computer generated images. Comm. Assoc. Comput. Machin. 311-317.

Prallet, B., Male, P., Neff, L. \& Baron, R. (1992) Identification of a functional mononuclear precursor of the osteoclast in chicken medullary bone marrow cultures. J. Bone Miner. Res. 7, 405-414.

Ren, Y.F., Zhao, Q., Malmstrom, H., Barnes, V. \& Xu, T. (2009) Assessing fluoride treatment and resistance of dental enamel to soft drink erosion in vitro: applications of focus variation 3D scanning microscopy and stylus profilometry. J. Dent. 37, 167-176.

Roodman, G.D. (2006) Regulation of osteoclast differentiation. Ann. N.Y. Acad. Sci. 1068, 100-109.

Schwartz, Z., Lohmann, C.H., Wieland, M., Cochran, D.L., Dean, D.D., Textor, M., Bonewald, L.F. \& Boyan, B.D. (2000) Osteoblast proliferation and differentiation on dentin slices are modulated by pretreatment of the surface with tetracycline or osteoclasts. J. Periodontol. 71, 586-597.

Soysa, N.S., Alles, N., Aoki, K. \& Ohya, K. (2009) Three-dimensional characterization of osteoclast bone-resorbing activity in the resorption lacunae. J. Med. Dent. Sci. 56, 107-112.

Sugawara, K., Hamada, M., Hosoi, S. \& Tamaoki, T. (1998) A useful method to evaluate bone resorption inhibitors, using osteoclast-like multinucleated cells. Anal. Biochem. 255, 204-210.

Takahashi, N., Sasaki, T., Tsouderos, Y. \& Suda, T. (2003) S 12911-2 Inhibits osteoclastic bone resorption in vitro. J. Bone Miner. Res. 18, 1082-1087. 
Takami, M., Suda, K., Sahara, T., Itoh, K., Nagai, K., Sasaki, T., Udagawa, N. \& Takahashi, N. (2003) Involvement of vacuolar H+ATPase in incorporation of risedronate into osteoclasts. Bone 32, 341349.

Umezu, A., Kaneko, N., Toyama, Y., Watanabe, Y. \& Itoh, H. (1989) Appearance of osteoclasts by injections of lipopolysaccharides in rat periodontal tissue. J. Periodontal Res. 24, 378383.

Vääraniemi, J., Halleen, J.M., Käärlonen, K., et al. (2004) Intracellular machinery for matrix degradation in bone-resorbing osteoclasts. J. Bone Miner. Res. 19, 1432-1440.

Walsh, C.A., Beresford, J.N., Birch, M.A., Boothroyd, B. \& Gallagher, J.A. (1991) Application of reflected light microscopy to identify and quantitate resorption by isolated osteoclasts. J. Bone Miner. Res. 6, 661671.

Witten, P.E., Hansen, A. \& Hall, B.K. (2001) Features of mono- and multinucleated bone resorbing cells of the zebrafish Danio rerio and their contribution to skeletal development, remodeling, and growth. J. Morphol. 250, 197-207.

Witten, P.E. \& Huysseune, A. (2009) A comparative view on mechanisms and functions of skeletal remodelling in teleost fish, with special emphasis on osteoclasts and their function. Biol. Rev. Camb. Philos. Soc. 84, 315-346.

Yamada, Y., Ito, A., Sakane, M., Miyakawa, S. \& Uemura, T. (2007) Laser microscopic measurement of osteoclastic resorption pits on biomaterials. Mater. Sci. Eng. C 27, 762-766. 